\title{
Nocturnal Hypoxemia, a Key Parameter in Overlap Syndrome
}

\author{
CORINA EUGENIA BUDIN ${ }^{1}$, ANCA DIANA MAIEREAN ${ }^{1}$, EDITH SIMONA IANOSI' ${ }^{2}$ ADRIANA SOCACI ${ }^{3}$, ANCA DANA BUZOIANU ${ }^{1}$, \\ TEODORA GABRIELA ALEXESCU1*, MIHAI OLTEANU ${ }^{4}$, ELENA RUSU5 ${ }^{5}$, COSMIN ALEC MOLDOVAN ${ }^{5}$, ROXANA MARIA NEMES \\ IIuliu Hatieganu University of Medicine and Pharmacy, 4 Louis Pasteur Str. 400349, Cluj Napoca, Romania \\ ¿University of Medicine, Pharmacy, Science and Tehnology Targu-Mures, Discipline of Pneumology, 38 Gh. Marinescu Str., \\ 540139, Tg. Mures, Romania, \\ ${ }^{3}$ Clinical Hospital for Infectious Diseases and Pneumology Dr. Victor Babes, 13 Gheorghe Adam Str., 300310, Timisoara, Romania \\ ¿University of Medicine and Pharmacy Craiova, 2 Petru Rares Str., 20039, Craiova, Romania \\ ${ }^{5}$ Titu Maiorescu University, Faculty of Medicine, 67A Gh. Petrascu Str. 031593, Bucharest, Romania
}

\begin{abstract}
The overlap syndrome (OS) is defined as a synergic relation between obstructive sleep apnea (OSA) and chronic obstructive pulmonary disease (COPD). Patients with overlap syndrome present the clinical features of each disorder to a greater or a lesser extend depending on the predominant disease. We assessed the main differences between patients with OS and patients with OSA and we highlight the importance of nocturnal hypoxemia on clinical status and management of the patients with overlap syndrome, in order to simplify OSA screening tests in patients with COPD. The study population included 62 selected patients divided in two groups: the first group - subjects diagnosed with OS and the second group - subjects with OSA, without the diagnostic of COPD. The majority of the patients were male, with a mean age of $55 \pm 9.84$ years in the OSA group and $65.5 \pm 10.32$ years in the OS group. The nocturnal hypoxemia was more important in the OS grup, with 276.83 minutes spent at a SpO2 below 90\% versus 132.98 minutes in the OSA group. The mean AHI was 57.7 \pm 29.244 events/hour of sleep in the OS group and $50.7 \pm 26.01$ events/hour of sleep in the OSA group. At the diagnosis, the mean daytime SpO2 was 90.9 $3.59 \%$ in the OS group and $95.9 \pm 1.57$ $\%$ in the OSA group. There were statistically significant differences between the two groups concerning age, AHI, Epworth Slepiness Scale, nocturnal desaturation, medium and minimum SpO2 during sleep, daytime SpO2 at the diagnosis and at 1-year follow-up, the presence of cardiovascular comorbidities such as pulmonary hypertension and heart failure. Our study showed that patients with COPD have OSA predictors that differ from those usually recognise in the general population. In OS patients, the most important parameter is the nocturnal hypoxemia. So, it is very useful that the clinicians be trained to include in the management of selected obese COPD patients, comprehensive sleep history, sleep hygiene and OSA screening because, in clinical practice, OSA is quite often underdiagnosed in these patients.
\end{abstract}

Keywords: COPD, OSA, overlap, AHI, desaturation

Chronic Obstructive Pulmonary Disease (COPD) is a common, preventable and treatable disease that is characterized by persistent respiratory symptoms and airflow limitation that is due to airway and/or alveolar abnormalities usually caused by significant exposure to noxious particles or gases [1] and tobacco [2]. COPD has become a problem of public health that occurs in $>10 \%$ of adults over 40 years of age and accounts for $>5 \%$ of physician office visits and $13 \%$ of all hospitalizations, with the majority of patients remaining undiagnosed and untreated $[3,4]$. The burden of COPD is increasing and new guidelines focus on symptom control and the impact of comorbid conditions. Obstructive sleep apnea (OSA) is a sleep-related breathing disorder that involves a decrease or complete halt in airflow despite an ongoing effort to breathe, resulting in nocturnal hypoxemia and arousal of sleep [5]. The prevalence of OSA is increasing with age. Although it is typically a condition affecting men, with a ratio of approximately 10:1 between men and women, the prevalence of OSA is about $10 \%$ among women. However, the sex disparity of OSA ends at the age of 55 years with a sharp rise among postmenopausal women [6-9].

The first who described the overlap syndrome (OS) was Flenley and it is defined as a synergistic relation between OSA and COPD [10]. There are some data about the prevalence of overlap syndrome. COPD and OSA are both common diseases affecting 10 and respectively $5 \%$ of the adult population over 40 years of age. Their coexistence was studied in the Sleep Heart Health Study, a large community-based cohort study, including as diagnostic tests polysomnography and spirometry, in which $0.5-1 \%$ of the participants had airflow obstruction [11,12]. Patients with the overlap syndrome will present the clinical features of each disorder to a greater or lesser extent depending on the predominant disease [13]. However, there are also likely to be additional clinical features to reflect the higher prevalence of hypoxemia, hypercapnia and pulmonary hypertension. Thus, morning headaches reflecting hypercapnia, cyanosis reflecting hypoxemia and peripheral edema reflecting cor pulmonale are probably common in overlap patients [14]. Given the impact of those comorbidities in patient quality of life and morbidity, it seems logical to investigate predictors that would help identify overlap subjects. Although age, gender, neck circumference have been shown to be good predictors in some epidemiologic studies, these predictors may vary according to the specific population studied [15]. An objective anamnesis and clinical examination, including anthropometrics data, medical history andscreening questionnaires regarding symptoms may be helpful in the initial evaluation of likely OSA in COPD patients. The recent report of Ustun et al. indicates that readily available objective data from medical records such as age, sex, BMI and the presence of co-morbidities such as hypertension may be superior to the traditional symptoms of snoring and excessive daytime sleepiness in predicting the likelihood of OSA[16]. 


\section{Experimental part}

Sixty-two patients were enrolled in this retrospective, observational, experimental cross-sectional study. The study, conducted on human subjects, had the approval of the Medical Ethics Committee, and each subject signed an informed consent according to current legislation. All the patients were diagnosed and treated in the Leon Daniello Clinical Hospital of Pneumology Cluj-Napoca, in the Sleep Laboratory. Enrolments began in august 2016 and ended in September 2018 and inclusion criteria included: age $\geq 18$ years old, diagnosis of OSA (mild, moderate or severe), COPD diagnosis according to GOLD criteria (GOLD I, II, III, IV). We collected anthropometric and demographic data including: age, gender, body mass index (BMI), neck circumference, apnea-hypopnea index, duration of nocturnal desaturations, the presence of associated cardiovascular diseases, defined as: diagnosis by a specialistor lack of medical documentation but patient undergoing treatmentfor: essential hypertension, ischemic heart disease, heart rhythm disorders, heart failure(table 1). We also achieved the Epworth Sleepiness Scale. All subjects were tested by a cardio-respiratory polygraph with 7 channels, recording nasal respiratory flow, SpO2, cardiac frequency, snoring, body position, thoracic respiratory effort and abdominal respiratory effort.

The diagnosis of COPD was established in accordance with the GOLD 2016 criteria. Diagnosis of Sleep Apnea Syndrome was performed based on a nocturnal cardio respiratorypolygraph, clinical examination, Epworth Sleepiness scale (ESS) and anamnestic data, according to AASM 2016 guidelines. Subjects were divided into two groups as follows: Group I - subjects with COPD diagnosed with OSA (OS) and group II - subjects diagnosed with OSAwithout COPD.

Data were recorded and processed using Microsoft Office Excel (Microsoft, Redmond, WA, USA). Statistical analysis was performed using IBM SPSS Statistics 17 (Statistical Package for the Social Sciences, SPSS Inc., Chicago, IL, USA). A value of $p<0.05$ was considered significant. The quantitative variables were reported as means \pm standard deviation, the ordinal variables as medians, whereas the qualitative variables were represented in absolute and relative frequency. The correlation coefficients were calculated between continuous and/or ordinal variables and their level of significance was assessed.

\section{Results and discussions}

As mentioned previously, the subjects were divided into two groups: subjects diagnosed with OS in the first group and subjects diagnosed with OSA (without COPD) in the second group. Each category included a total of 31 patients. The study population had homogeneous demographic and anthropometric characteristics. Of the 62 patients enrolled in the study, in terms of gender, the prevalence of overlap syndrome was higher in males, in both groups, $83.87 \%$ in

Table 1

THE DEMOGRAPHIC AND ANTHROPOMETRIC PARAMETERS STUDIED

\begin{tabular}{|c|c|c|c|}
\hline Parameter & $\operatorname{OSA}(n=31)$ & $\begin{array}{c}\text { OS } \\
(\mathrm{OSA} \text { and } \mathrm{COPD})(\mathrm{n}=31)\end{array}$ & Pvalue \\
\hline Gender (male) & $20(64.51 \%)$ & $26(83.87 \%)$ & 0.082 \\
\hline Age (years) & $55 \pm 9.84$ & $65.6 \pm 10.32$ & $0.000001^{*}$ \\
\hline $\mathrm{BMI}\left(\mathrm{kg} / \mathrm{m}^{2}\right)$ & $35.3 \pm 4.88$ & $36.4 \pm 4.78$ & 0.413 \\
\hline Neck circumference $(\mathrm{cm})$ & 48.41 & 44.62 & 0.022 \\
\hline Epworth Sleepiness Scale & 11.23 & 14.19 & $0.003^{*}$ \\
\hline $\begin{array}{c}\text { AHI (Events/hour of sleep) at the } \\
\text { diagnosis }\end{array}$ & $50.7 \pm 26.01$ & $57.7 \pm 29.244$ & 0.331 \\
\hline $\begin{array}{l}\text { AHI (Events/hour of sleep) at } 1 \\
\text { year follow-up }\end{array}$ & $2.36 \pm 1.26$ & $3.62 \pm 2.27$ & $0.01^{*}$ \\
\hline Saturation $<90 \%$ (Minutes) & 132.98 & 276.83 & $0.000001^{*}$ \\
\hline Saturation $<85 \%$ (Minutes) & $48.22 \pm 67.1$ & $139.26 \pm 122.34$ & $0.001^{*}$ \\
\hline Saturation $<80 \%$ (Minutes) & $24.53 \pm 47.06$ & $60.53 \pm 80.01$ & $0.035^{*}$ \\
\hline Minimum night $\mathrm{SpO} 2$ & $77.7 \pm 7.02 \%$ & $68.53 \pm 10.15 \%$ & $\approx 0.001^{8}$ \\
\hline Medium night $\mathrm{SpO} 2$ & $87.83 \pm 2.91 \%$ & $85.51 \pm 4.25 \%$ & $0.016^{*}$ \\
\hline Daytime $\mathrm{SpO} 2$ at the diagnosis & $95.9 \pm 1.57 \%$ & $90.9 \pm 3.59 \%$ & $=0.001^{8}$ \\
\hline Daytime SpO2 1-year follow-up & $97.1 \pm 0.9 \%$ & $94.3 \pm 2.21 \%$ & $<0.001^{8}$ \\
\hline Pulmonary hypertension (PH) & $3(9.67 \%)$ & $9(29.03 \%)$ & $0.016^{*}$ \\
\hline Heart Failure (HF) & $5(16.13 \%)$ & $20(64.65 \%)$ & $\approx 0.001^{8}$ \\
\hline
\end{tabular}


OS group $(n=26)$ and $64.51 \%(n=20)$ in the OSA group. Similar results were also obtained by Soler et al. in a study conducted on a total of 44 patients, of which $54 \%$ were men [17]. Other studies have shown that males diagnosed with COPD had a higher predisposition to develop OSA [18].

On the other hand, referring to age, in the OS group the average age was 65.6 years, and in the OSA group it was 55 years $(p=0.000001)$, with a high statistical significance of the difference between the two groups (table 1). It is known that aging becomes an independent risk factor for OSA and COPD, data confirmed by the study by Chaouat $A$. et al. [19].

In the present study there was no statistically significant difference in $\mathrm{BMI}$, so values in both groups were uniform. Xavier et al. have demonstrated that BMI $\geq 25 \mathrm{~kg} / \mathrm{m}^{2}$ is a good predictor for OSA [17]. In addition, our study demonstrates thatin the OS group the increasedBMI was associated with a higher AHI (Pearson correlation coefficient $r=0.695, p<0.001$ ) (fig. 1). Based on the observation that a BMl greater than $25 \mathrm{~kg} / \mathrm{m}^{2}$ is associated with better survival, ithas been proposed that obesity could be protective in COPD[20]. Also, it is plausible that the effects of air trapping on the upper airway could overcome the effects of airw ay collapse due to obesity or emphysema [21].Taking into consideration the neck circumference as an element that indicates central obesity, our study found a difference of $3.79 \mathrm{~cm}(48.41 \mathrm{~cm}$ versus $44.62 \mathrm{~cm}$ ) (table 1) between the OS group and the OSA group, possibly due to anatomical and physiological factors and treatment with
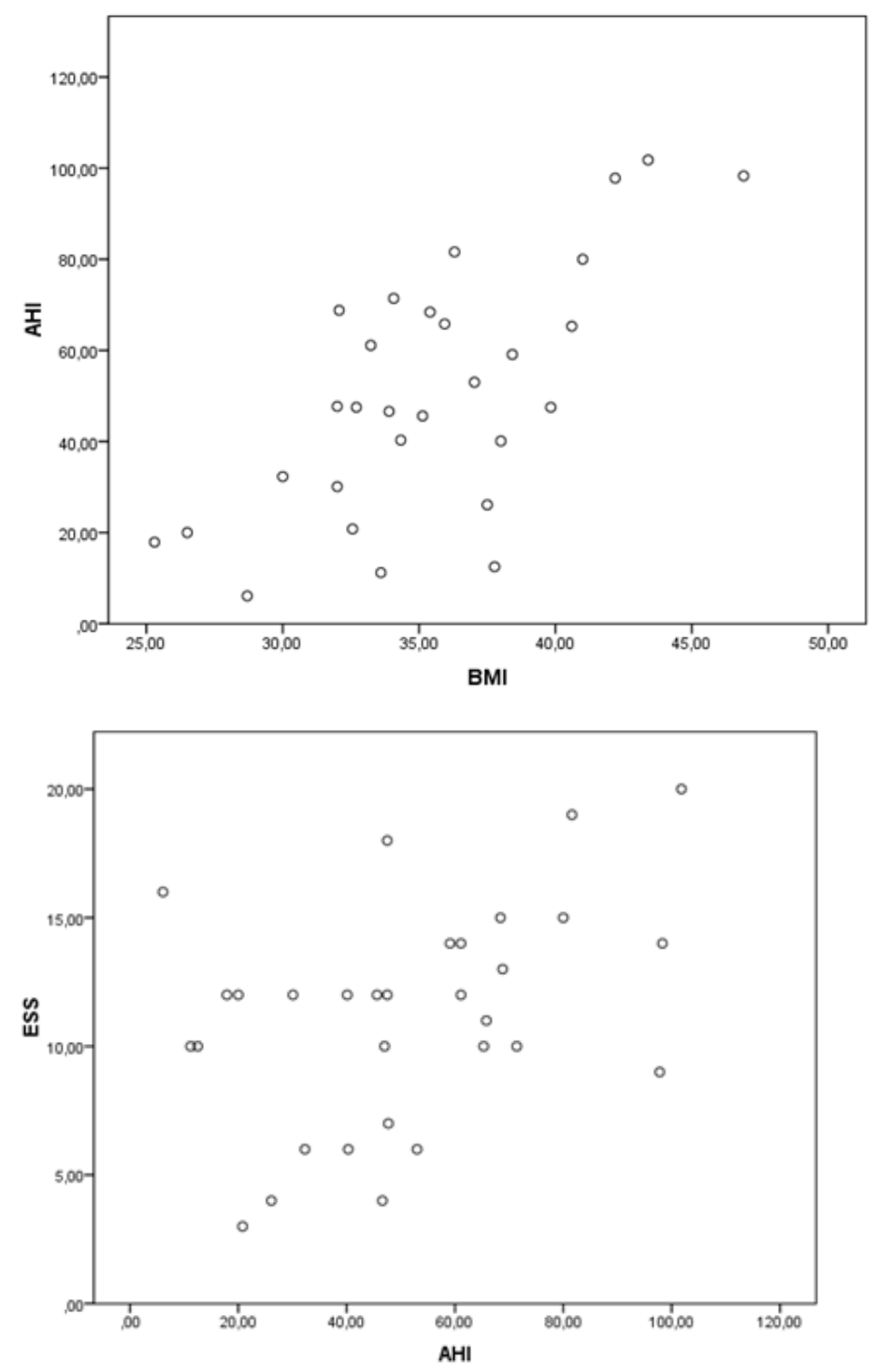

corticosteroids that increase fat deposition in the neck region. Other studies confirmed that central obesity is a risk factor for OSA in the general population $[22,23]$. It is known that OSA has an independent contribution to the pathogenesis of metabolic abnormalities, including type 2 diabetes, the metabolic syndrome and fatty liver disease, and a study pointed to a strong correlation between $\mathrm{AHI}$, average SpO2 and $\mathrm{HbAlc}(p<0.001)$. It is clear that future studies are needed to better understand this relationship [24]. According to these findings, one of the mostimportant interventions in the treatment of OSA is the nutrition program, implemented to obtain weight loss in order to reduce the apnea-hypopnea index and the severity of OSA and, inselected cases with associated craniofacial deformities,early orthodontic treatment could be beneficial [25-27].

Regarding OSA, the most important symptom is excessive daytime sleepiness because it can cause road and work accidents. The ESS has been used for decades as a screening tool for OSA [28]. In the Sleep Heart Health Study, an increased ESS score was associated with severity of sleep-disordered breathing (SDB), habitual snoring, male gender and other important clinical symptoms[29]. The median ESS is 14.19 in the OS group, whereas in the OSA group, the median ESS is $11.23(p=0.003$ ) (table 1$)$. In our study, it was a significant correlation between ESS and $\mathrm{AHI}$ in the OS group (Spearman correlation coefficient $\rho=0.373, p=0.038$ ) (fig. 2), so the severity of OSA was predicted by the ESS scale in the OS patients. The patients with OS have poor sleep quality and disrupted sleep

Fig. 1. Association between $\mathrm{AHI}$ and $\mathrm{BMI}$ in the OS group

Fig.2. The association between AHI and ESS in the OS group 


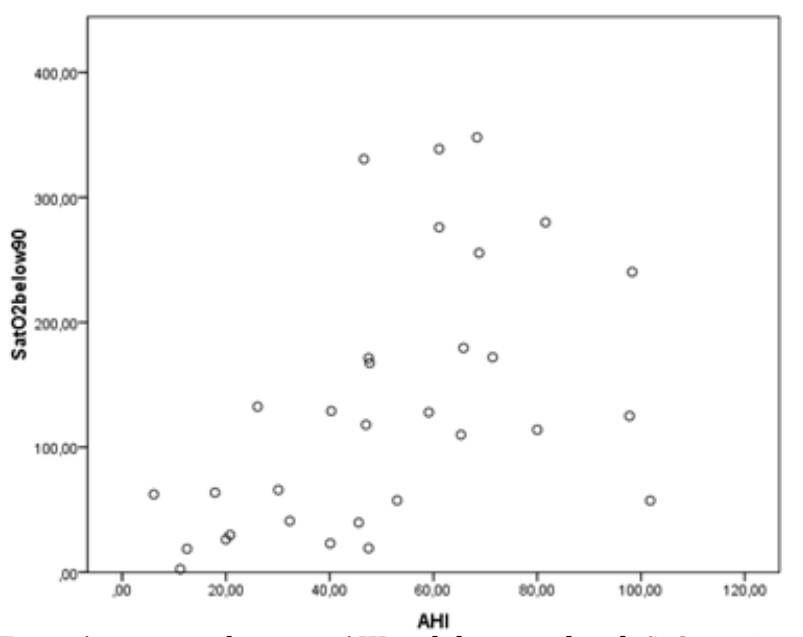

Fig. 3. Association between $\mathrm{AHI}$ and the period with $\mathrm{SaO} 2 \leq 90 \%$ in the OS group

architecture because of the respiratory symptoms such as cough or dyspnea that disrupt sleep. Sleep disturbance is one of the most common symptoms reported by COPD patients, occurring in $\sim 40 \%$ of patients in one large study $[30,31]$. These patients have problems initiating or maintaining sleep, and have increased light sleep and reduced REM sleep, frequent sleep stage shifts and microarousals.Although ESS grades the severity of sleepiness, this symptom alone may be very common in COPD and, therefore lacking in predictive value[30,32].

In our study, the mean $\mathrm{AHI}$ in the OS group was $57.7 \pm 29.244$ and in OSA group was $50.7 \pm 26.01$, without any statistical significance $(p=0.331)$ (table 1$)$, and the same results were obtained by Radwan L. et al. [33]. In clinical practice, since overlap patients are particularly prone to oxygen desaturation during sleep, continuous overnightmonitoring of arterial oxygen represents the most important variable, particularly because the recording provides data on the frequency of oxygen desaturation index (ODI). So, the ODI provides a measure of intermittent hypoxemia, which appears to be superior to the $\mathrm{AHI}$ in predicting cardio-vascular co-morbidity [34]. Also, COPD has been recognized to be associated with oxygen desaturation during sleep. A core element of OSA is intermittent nocturnal oxygen desaturation associated with apnea and hypopnea, and patients with overlap syndrome demonstrate even greater degrees of oxygen desaturation. Overlap patients have worse sleep-related chronic hypoxemia and hypercapnia than patients with COPD or OSA alone. OSA has a similar prevalence in COPD patients asin a general population of similar age, but oxygen desaturation during sleep is more pronounced when the two conditions coexist [12]. This fact was demonstrated in our study, with a mean period of $\mathrm{SaO}_{2} \leq 90 \%$ in the OS

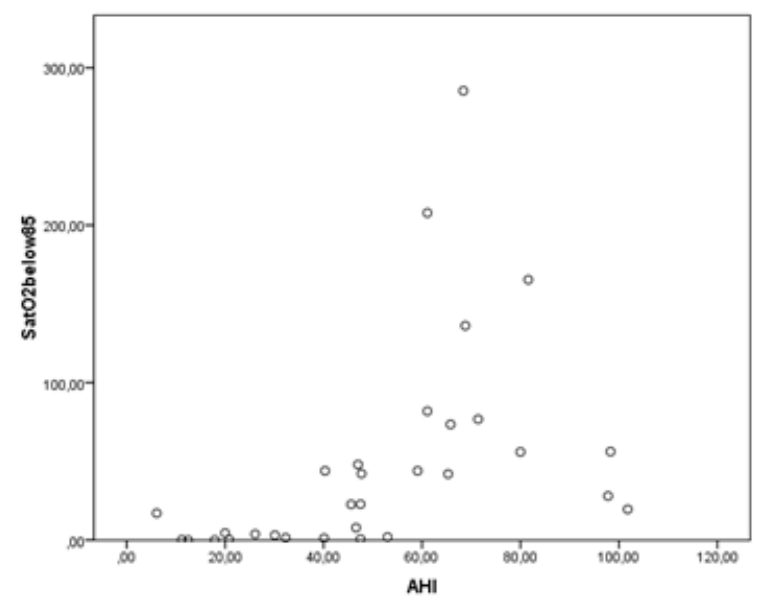

Fig. 4. Association between $\mathrm{AHI}$ and the period with $\mathrm{SaO} 2 \leq 85 \%$ in the OS group

group of 276.83 min versus 132.98 min in the OSA group (table 1), a difference with high statistical significance $(p=0.000001)$. Also, the nocturnal hypoxemia is associated with the increase of $\mathrm{AHI}$ in the OS patients (Pearson correlation coefficient $r=0.505, p=0.004$ ) (fig. 3). Furthermore, the mean period with $\mathrm{SAO}_{2} \leq 85 \%$ in the OS group was $139.26 \pm 122.34$ min, versus $48.22 \pm 67.1$ min in the OSA group (table 1). Once the AHI increased, the period of desaturation increased too, in the OS group (Pearson correlation coefficient $r=0.455, p=0.01$ ) (fig. 4). Also, there are significant differences regarding the period of desaturation below $80 \%$ between the two groups, with a mean period of $60.53 \pm 80.01 \mathrm{~min}$ in the OS group, versus $24.53 \pm 47.06 \mathrm{~min}$ in the OSA group $(p=0.235)$ (table 1). This means that the time spent in nocturnal hypoxemia with SpO2 lower than $80 \%$ correlates with AHlin the OS subjects (Pearson correlation coefficient $r=0.599$, $p<0.001$ ) (fig. 5). These positive correlations between nocturnal hypoxemia and $\mathrm{AHI}$ areprobably a consequence of overlap syndrome, because patients with OS have lower baseline oxygen saturation during sleep, which results in greater oxygen desaturation during apnea or hypopnea as a natural consequence of the oxyhemoglobin dissociation curve [12].

In order to confirm the nocturnal hypoxemia, we compared the minimum and the medium nocturnal SpO2 between OS group and OSA group. There were significant differences regarding the minimum $\mathrm{SpO}_{2}$ between the two groups $(p<0.001)$, with a mean minimum $\mathrm{SpO}_{2}$ of $68.53 \pm 10.15 \%$ in the OS group, versus $77.7 \pm 7.02 \%$ in the OSA group. Also, there are significant differences regarding the mean nocturnal $\mathrm{SpO}$, between the two groups, with a mean $\mathrm{SpO}_{2}$ of $85.51 \pm 4.25 \%$ in the OS group, versus

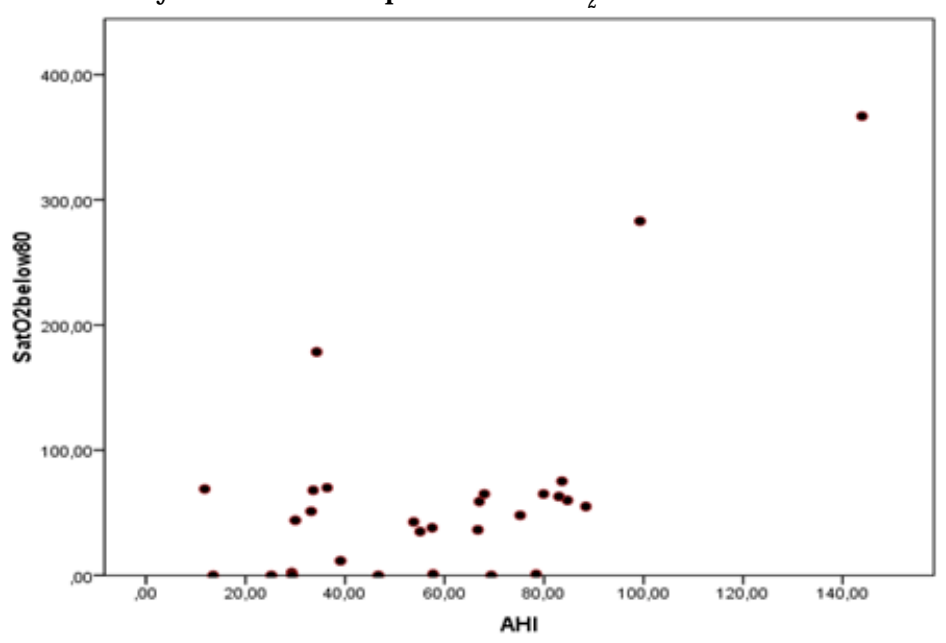

Fig. 5. Association between $\mathrm{AHI}$ and the period with $\mathrm{SaO} 2 \leq 80 \%$ 
$87.83 \pm 2.91 \%$ in the OSA group.The nocturnal oxygen desaturation in overlap patients typically demonstrates a pattern of intermittent desaturation from a baseline hypoxemiaduring sleep, which contrasts with the usual pattern of intermittent desaturation from a relatively normal baseline saturation in patients with OSA alone.

We observed a significant improvement regarding the daytime $\mathrm{SpO}_{2}$ between the two groups, comparing the $\mathrm{SpO}$ at the diagnnosis and after 1-year follow-up. The mean value of daytime $\mathrm{SpO}_{2}$ at the diagnosis was $90.9 \pm 3.59 \%$ in the OS group versus $95.9 \pm 1.57 \%$ in the OSA group $(p<0.001)$.At 1-year follow-up the mean daytime SpO2 was $94.3 \pm 2.21 \%$ in the OS group, versus $97.1 \pm 0.9 \%$ in the OSA group ( $p<0.001)$. We conclude that the treatment with CPAP along with the treatment for COPD according to the guidelines improved the clinical status and the daytime saturation.Several mechanisms may explain these results, such as bronchodilation, reduction of respiratory load, improvement of ventilation/perfusion ratio, as well as changes in the respiratory center and in the sensitivity of chemoreceptors. The same results were found in a study that included 55 patientswhich proved significant improvements in $\mathrm{FEV}_{1}, \mathrm{FVC}$, and $\mathrm{PaCO}_{2}$ after 6 months of nasal CPAP therapy and specific therapy for COPD [35].

Prolonged nocturnal hypoxemia and systemic inflammation represents important contributing factors to the development of cardiovascular disease and it is notable that cardiovascular and metabolic comorbidities are recognized as a common complication of both COPD and OSA [22, 36, 37]. Moreover, pronounced nocturnal oxygen desaturation in patients with OSis an important factor in the development of pulmonary hypertension (PH), which is especially common in such patients [21]. In our study, OS patients experienced pulmonary hypertension more frequently than patients diagnosed with OSA $(P=0.016)$ (table 1), probably because of the acute rises in pulmonary artery pressure (Ppa) and pulmonary vascular resistance (PVR), coinciding with sleep induced apneas and secondary hypoxemia [38,39]. Several studies have shown that a significant proportion of OSA patients also have an elevated Ppa during the day [39-41], but still the etiology of pulmonary hypertension in these patients is uncertain. Atthe same time, we found in our study, that $64.65 \%$ of the subjects with OSpresented Heart Failure (HF) versus $16.13 \%$ of those with OSA, a very high statistically significant correlation $(p<0.001)$ (table 1).

The importance of screening programs is evident, moreover because some studiesshowed that only overweight itself produce early changes in cardiovascular status of the patient by decreasing the left ventricular ejection fraction, thickening the interventricular septum, increasing left ventricular mass and implementing early diastolic dysfunction [42].Thus, one could expect that cardiovascular disease would be particularly prevalent in patients with overlap syndrome, but there are limited data on this relationship.

Regarding the treatment of overlap syndrome, the most effective and preferred treatment is the therapy with continuous positive airway pressure( (CPAP), along with the specific treatment for COPD according to the guidelines. The role of CPAP is to reduce the AHI, to correct the desaturations and to improve the quality of sleep. In our study, we observed that there are significant benefits of the CPAP therapy in the two groups, with a mean value of residual $I A H$ of $3.62 \pm 2.27$ in the OS group, versus $2.36 \pm 1.26$ in the OSA group $(p=0.01)$ (table 1$)$.

Treatment of overlap syndrome is targeted at each disease state as per guidelines. Patients with overlap syndrome who are efficiently treated with CPAP will have adequate nocturnal oxygen saturation, but the therapeutic success is primarily ensured by the patients'compliance [43]. In addition, there are other concerns that must be taken into account once the CPAP therapy is initiated at home, like microclimate and the hygiene of CPAP device, including masks and tubing [44-46]. Some studies demonstrated the presence of various microbiological and inorganic structures on the inner surface of CPAP masks and tubes, emphasizing the risk of microbial and inorganic elements inhalation into the upper and lower airways. Once they arrive in the respiratory way, in patients with COPD these microorganisms can reduce the compliance to CPAP therapy and moreover can produce exacerbations of the respiratory symptomatology $[45,46]$ with a high risk of hospitalization and other infections [47-49].

\section{Conclusions}

Our study is important in order to evaluate the patients with overlap syndrome in a complex way and to understand that patients with COPD have OSA predictors that differ from those usually recognized in the general population. The most important element in diagnosis and follow-up for patients with OS is the total nocturnal time of desaturations, because, as our study shows, the subjects with OS have more nocturnal desaturations, with a negative impact on symptomatology, cardiovascular comorbidities and management.The mainstay of treatment for patients diagnosed with overlap syndrome is continuous positive airway pressure, besides the treatment for COPD according to guidelines. It is important that clinicians should be trained that the management of selected obese COPD patientsought to include comprehensive sleep history, sleep hygiene and OSA screening, because in most of the cases, in clinical practice OSA is underdiagnosed in these patients.

\section{References}

1.*** Global Initiative for Chronic Obstructive Lung Disease. Global Strategy for the Diagnosis, Management, and Prevention of COPD. Bethesda (MD): GOLD; 2016.

2.POSTOLACHE, P., NEMES, R. M., PETRESCU 0; et al. Surgical J ournalRevista Medico-Chirurgicala, 119, nr. 1, 2015, p.77

3.MANNINO, DM., BUIST AS., Lancet, 370, nr. 9589, 2007, p. 765

4.MININO, AM., MURPHY, SL., XU, J., KOCHANEK, KD. Natl. Vital Stat. Rep., 59, nr. 10, 2011, p.1

5.*** THE REPORT OF AN AMERICAN ACADEMY OF SLEEP MEDICINE TASK FORCE. Sleep,22, nr. 5, 1999, p. 667

6.BIXLER,EO., VGONTZAS, AN., LIN, HM., ET AL.,Am. J.Respir. Crit. Care Med., 163, nr. 3, 2001, p.608

7.DANCEY, DR., HANLY, PJ ., SOONG, C., LEE, B., HOFFSTEIN, V., Chest, 120, nr. 1, 2001, p.151

8.TISHLER, PV., LARKIN, EK., SCHLUCHTER, MD., REDLINE, S.,JAMA, 289, nr. 17, 2003, p.2230

9.YOUNG, T., PALTA, M., DEMPSEY, J., SKATRUD, J., WEBER, S., BADR, S.,N. Engl. J. Med., 328, nr. 17, 1993, p. 1230

10.FLENLEY, DC.,Clin. Chest Med., 4, nr. 6,1985, p. 651

11.SANDERS, MH., NEW MAN, AB., HAGGERTY, CL., ETAL. Am. J. Respir. Crit. Care Med., 167, nr.1, 2003, p.7

12.WEITZENBlum, E., CHAOUAT, A., KESSLER, R., CANUET, M., Proc. Am.Thorac. Soc., 5, nr.2, 2008, p. 237

13.JIMBOREAN, G., SZASZ, S., SZATHMARY, M., ET AL..Rev.Chim. (Bucharest), 69, no. 4, 2018, p.1014

14.McNICHOLAS, WT., Chest, 152, nr. 6, 2017, p. 1318

15.PEPPARD, PE., YOUNG, T., BARNET, JH., PALTA, M., HAGEN, EW., HLA, KM., Am. J.Epidemiol., 117, nr. 9, 2013, p. 1006

16.USTUN, B., WESTOVER, MB., RUDIN, C., ET AL., J.Clin. Sleep Med., 12 nr. 2, 2016, p.161 
17.SOLER, X., LIAO, SY., MARIN, JE., LORENZI-FILHO, G., JEN, R., DEYOUNG, P., OWENS, RL., RIES, AL., MALHOTRA, A.,Plos One,2017, https://journals. plos.org/plosone/article?id=10.1371/journal. pone.0177289,

18.SCOTT, A., BALTZAN, M., WOLKOVE, N.,Can. Respir. J., 21, nr. 3, 2014, p.171

19.CHAOUAT, A., WEITZENBLUM, E., KRIEGER, J., IFOUNDZA, T., OSWALD, M., KESSLER, R.,Am. J.Respir. Cri.t Care Med., 151, nr. 1, 1995, p. 82

20.POULAIN, M.,DOUCET,M., MAJ OR, GC.,DRAPEAU, V., SERIES, F.,BOULET, L., TREMBLAY, A., MALTAIS,F.,CMAJ ., 174, nr. 9, 2006, p. 1293

21.KRACHMAN SL, TIWARI R, VEGA ME, YU D, SOLER $X$, JAFFE F, ET AL.,Ann. Am. Thorac. Soc., 13, nr.7, 2016, p. 1129

22.BONSIGNORE, MR., BOREL, AL., MACHAN, E., GRUNSTEIN, R.,Eur. Respir. Rev., 22, nr. 129, 2013, p. 353

23.RUSU, A., TODEA, D., ROSCA, L., NITA,C., BALA, C. Acta Diabetol., 49, nr.2, 2012, p. 105

24.OTELEA, M.R., TRENCHEA, M., ARGHIR, O.C., VELESCU, L., DANTES, E., BECHIR, E.S., ELSAAFIN, M., RASCU, A.,Rev. Chim.(Bucharest), 69, no.1, 2018, p. 282

25.DOBROSIELSKI, DA., PAPANDREOU,C., PATIL, SP., SALAS-SALVADO, J.,Eur. Respir. Rev., 26, nr. 144, 2017, 160110.long

26.TODEA, D., CADAR, O., SIMEDRU, D., ROMAN, C., TANASELIA, C., SUATEAN, I.,NAGHIU, A.,Not. Bot.Horti.Agrobo.,42, nr. 2, 2014, p.523 27.RADESCU, O.D., ALBU, S., BACIUT, M., S., COMAN, A.C., BECHIR, E.S., PACURAR, M., TODEA, D.A., Mat. Plast., 54, no. 3, 2017, p: 473 28.J OHNS MW.,Sleep, 14, nr. 6, 1991, p. 540

29.GOTTLIEB,DJ ., WHITNEY, CW., BONEKAT, WH., IBER,C., JAMES, GD., LEBOWITZ, M., ET AL., Am. J.Respir. Crit. Care Med., 159, nr. 2, 1999, p.502.

30.CORMICK, W., OLSON, LG., HENSLEY, MJ ., SAUNDERS, NA.,Thorax, 41, nr. 11, 1986, p. 846

31.COLLOP, N.,Respiration, 80, nr.1, 2010, p.78

32.RUSU, A., NITA, C., TODEA, D., ROSCA, L., BALA, C., HANCU, N. Acta Endo. (Buc), 7, nr 2, 2011, p. 163

33.RADWAN, L., MASZCZYK, Z., KOZIOROWSKI, A., KOZIEJ, M., CIESLICKI, J., SLIWINSKI, P., ZIELINSKI, J., Eur. Respir. J., 8, nr. 4, 1995, p.542
34.TKACOVA, R., MCNICHOLAS, WT., JAVORSKY, M., ET AL.,Eur. Respirat. J., 44, nr.4, 2014, p.931

35.DE MIGUEL J, CABELLO J, SANCHEZ-ALARCOS J M, ALVAREZ-SALA R, ESPINOS D, ALVAREZ-SALA JL.,Sleep Breath, 6, nr. 1, 2002, p. 3 36.MCNICHOLAS WT.,Am. J. Respirat. Crit. Care Med., 180, nr.8, 2009, p. 692

37.BRADLEY, TD., FLORAS, JS.,Lancet, 373, nr. 9657, 2009, p.82 38.COCCAGNA, G., MANTOVANI, M., BRIGNAN,I F., PARCHI, C., LUGARESI, E., Bull.Physiopathol.Respir.,8, nr. 5, 1972, p. 1159 39.TILKIAN, AG., GUILLEMINAULT, C., SCHROEDER, JS., LEHRMAN, KL., SIMMONS, FB., DEMENT, WC.,Ann. Intern. Med., 85, nr. 6, 1976, p.714

40.SHEPARD,JW., Hemodynamics in obstructive sleep apnea. In: Fletcher EC, ed. Abnormalities of respiration during sleep. Orlando, FL: Grune\& Stratton, 1986, p. 39

41.SCHROEDER,J S., MOTTA, J., GUILLEMINAULT, C., Hemodynamic studies in sleep apnea. In: Guilleminault C. Dement WC, eds. Sleep apnea syndromes. New York: Alan R. Liss, 1978, p.177-96.

42.ALEXESCU, T., COZMA, A., SITAR-TAUT, A., NEGREAN, V., HANDRU, M., MOTOCU, M., TOHÃNEAN,N., LENCU, C., PARA, I., Rom. J. Intern. Med., 54, nr. 3, 2016, p.161

43.BECKER, HF., PIPER, AJ ., FLYNN, WE., ET AL.,Am. J. Respir. Crit. Care Med., 159, nr. 1, 1999, p. 112

44.TODEA, DA., SUATEAN, I., COMAN, AC., ROSCA,LE.,Not. Bot.Horti. Agrobo., 41, nr 2, 2013, p. 646

45.COMAN, AC., TODEA, DA., POPA, E., RADU, T., CADAR, O., BORZAN, C., J. Optoelectron. Adv. M., 17, nr. 9-10, 2015, p. 1563

46.CHIN, CJ .,GEORGE, C., LANNIGAN, R., ROTENBERG, B.,J .Clin. Sleep. Med., 9, nr. 8, 2013, p.747

47.TANTU, M.M., MAN, G.M., PAUNESCU, A., PLESA, C.F., NEMES, R.M., NICOLAE, C., ROGOZEA, L.M., et al., Rev. Chim. (Bucharest), 69, no.11, 2018, p. 3001

48.RUSU, E., SARBU I., CRISTESCU C, COCULESCU B., MOLDOVAN H., PETRUT S., MURESAN A., VASSU T., PELINESCU D. Rev Chim (Bucharest), 67, no. 12, 2016, p. 2417

49.MITACHE, M., GHEORGHE, I., TOTEA, G., BLEOTU, C., CURUTIU, C., COCHIOR, D., RUSU, E., CHIFIRIUC, M.C., Rev. Chim. (Bucharest), 68, no., 5, 2017, p.997

Manuscript received: 14.10 .2018 